\title{
Identifikasi Kesesuaian Karakteristik Generasi Y dan Budaya Organisasi Terhadap Deviant Workplace Behavior pada PT. ABC
}

\author{
Sabrina Heriza Rangkuti*), Yuniaristanto dan Roni Zakaria \\ Program Studi Teknik Industri , Fakultas Teknik, Universitas Sebelas Maret \\ Jalan Ir. Sutami 36A, Surakarta 57126
}

DOI: 10.20961/performa.17.2.19030

\begin{abstract}
Abstrak
Di Indonesia, mengkaji generasi $Y$ merupakan tantangan karena penelitian seputar generasi $Y($ gen- $Y$ ) sangat terbatas, terutama untuk mengkaji karakteristik atau persepsi generasi ini. Salah satu perusahaan MRO Indonesia memiliki sekitar 4.400 karyawan, sekitar 65\% karyawannya termasuk gen-Y. Budaya organisasi adalah salah satu strategi yang dapat dipertimbangkan oleh perusahaan. Budaya organisasi menjadi elemen penting dalam menentukan norma, sikap, dan nilai sosial yang harus dipertimbangkan oleh organisasi untuk mengatasi masalah deviant workplace behavior. Tujuan dari penelitian ini adalah untuk mengetahui karakteristik karyawan gen-Y serta melihat hubungan antara karakteristik gen-Y dan budaya organisasi dengan deviant workplace behavior. Hasil yang diperoleh dari penelitian ini adalah beberapa karakteristik gen-Y menurut Murphy dan Davidshofer (2007) yang dimiliki oleh karyawan gen-Y, hanya karakteristik aksi kelompok yang berpengaruh terhadap karakteristik gen-Y pada PT. ABC. Hal ini berarti bahwa karyawan gen-Y di PT. $A B C$ belum mampu mengembangkan potensi yang dimiliki oleh Gen-Y secara umum. Seperti potensi optimis dan multitasking yang akan sangat bermanfaat bagi perusahaan tetapi belum pengaruh secara signifikan.
\end{abstract}

Kata kunci: budaya organisasi, deviant workplace behavior, generasi $Y$

\begin{abstract}
In Indonesia, knowing $Y$ generation (gen- $Y$ ) is a challenge because the research of this generation is very limited, especially to review the characteristic or perception of this generation. One of the MRO companies in Indonesia has about 4,400 employees and $65 \%$ of its employees are gen-Y. Organizational culture is one of the strategies considered by the company. Organizational culture become an important element in desigining norms, attitude and social values that must be considered with an organization to overcome deviant workplace behaviour problems So, the purpose of this study is to characterize the employee gen- $Y$ in the MRO company and to see the relationship of gen- $Y$ characteristics and organizational culture to the deviant workplace behavior. The results obtained from this research survey are some characteristics of gen-Y according to Murphy and Davidshofer (2007) owned by employees gen-Y at PT. ABC and only group action characteristics that have an effect on Y generation characteristics on PT. ABC. This can mean the generation of employees gen-Y at PT. ABC has not developed the potential which should belong to gen-Y in general. Like the potential to be optimistic and multitasking that would be very useful to the MRO company but has not had any influence.
\end{abstract}

Keywords: organizational culture, deviant workplace behavior, Y generation

\section{Pendahuluan}

PT. ABC merupakan perusahaan yang menyediakan jasa MRO (Maintenance, Repair, and Overhaul) yang terbesar di Indonesia dan salah satu yang terkemuka di Asia Pasifik dengan pengalaman lebih dari 60 tahun. PT. ABC memiliki visi untuk menjadi perusahaan MRO yang tergolong dalam 10 terbaik di dunia dengan target tahun 2020. Dalam mencapai visi tersebut, PT. ABC memiliki misi yaitu menyediakan solusi perawatan pesawat terbang yang terpadu dan handal sebagai kontribusi dalam mewujudkan lalu lintas udara yang aman dan menjamin kualitas kehidupan umat manusia. PT. ABC juga memiliki strategi untuk mendukung tercapainya visi dan misi perusahaan yaitu dengan program "Born to be Great". Program "Born to be Great" memiliki 3 aspek yaitu human centric, business expansion, and technology driven. Adapun nilai-nilai perusahaan yang berlaku saat ini, yaitu Concern for People, Integrity, Professional, Teamwork, dan Customer Focused.

${ }^{*}$ Korespondensi : yuniaristanto@ @ft.uns.ac.id 
Visi dan misi membutuhkan bantuan yaitu dukungan dari individu setiap pegawai yang memiliki komitmen dan kompetensi yang mampu diandalkan dalam perspektif ilmu, perilaku, berawal dari values yang dikembangkan dalam organisasi yang menjadi dasar terciptanya budaya kerja pada perusahaan tersebut (Nurcahyo, 2015). Budaya kerja adalah kebiasaan yang dilakukan berulang-ulang oleh pegawai dalam suatu organisasi, pelanggaran terhadap kebiasaan ini memang tidak ada sangsi tegas, namun dari pelaku organisasi secara moral telah menyepakati bahwa kebiasaan tersebut merupakan kebiasaan yang harus ditaati dalam rangka pelaksanaan pekerjaan untuk mencapai tujuan (Nawawi, 2005). Sikap-sikap dan nilai-nilai yang telah mengkristal dalam organisasi akan menuntun pegawai untuk berperilaku sesuai dengan sikap dan nilai yang diyakini. Dengan kata lain, budaya organisasi akan mempengaruhi anggota organisasi dalam mencapai tujuan organisasi. Hal ini menunjukan bahwa budaya kerja pada suatu perusahaan pun tidak lepas dari bagaimana sumber daya manusia yang dimiliki oleh perusahaan.

Generasi adalah sebuah kelompok yang terdiri dari individu yang memiliki kesamaan dalam rentang usia, dan berpengalaman mengikuti peristiwa sejarah penting dalam suatu periode waktu yang sama (Mannheim, 1923). De Meuse (2009) mengatakan bahwa terdapat 4 generasi angkatan kerja di dalam organisasi yang ditentukan berdasarkan tahun lahir, yaitu boomers (1946-1964), generasi X (1965-1977), dan generasi Y (19771994). Di Indonesia, mengenal generasi Y adalah sebuah tantangan tersendiri karena studi tentang generasi ini sangat terbatas atau bahkan dapat dikatakan sangat jarang literatur terkait dengan generasi ini, khususnya untuk mengkaji karakteristik ataupun persepsi dari generasi ini (Budiman, 2008). Menurut Bappenas (2015), jumlah millennials di Indonesia adalah 24 juta orang dengan jumlah penduduk mencapai 225 juta penduduk. Hal ini dapat dikatakan bahwa 33\% dari penduduk Indonesia adalah milennials.

Budaya organisasi menjadi elemen penting dalam perilaku karyawan, merancang ulang norma, attitude dan nilai sosial merupakan hal penting yang harus dilakukan suatu organisasi untuk mengatasi permasalahan deviant workplace behavior (Appelbaum, 2008). Deviant workplace behavior atau perilaku menyimpang di dunia kerja didefinisikan sebagai perilaku yang secara sengaja melanggar norma-norma organisasi yang signifikan, sehingga mengancam kesejahteraan organisasi atau anggotanya, atau keduanya. Norma-norma tersebut adalah kebijaksanaan perusahaan yang melarang perilaku-perilaku tertentu, seperti mencuri. Normanorma tersebut juga bisa merupakan peraturan tidak tertulis (Robbins, 2008).

Perilaku menyimpang ditempat kerja dibagi menjadi dua kelompok yaitu perilaku menyimpang positif dan menyimpang negatif (Appelbaum, 2007). Perilaku menyimpang positif didefinisikan sebagai perilaku yang disengaja yang menyimpang dari norma kelompok dengan cara yang terhormat (Speitzer dan Sononshein, 2004). Perilaku menyimpang negatif adalah perilaku sukarela yang melanggar norma organisasi yang mengecam kesejahteraan sebuah organisasi, anggotanya atau bahkan keduanya (Robinsson dan Bennett,1995). Saat ini, PT. ABC memiliki sumberdaya sekitar 4.400 pegawai dan $65 \%$ pegawainya adalah generasi $\mathrm{Y}$. Generasi Y adalah salah satu generasi yang paling mencolok karena terkenal dengan keragaman yang berada di dalamnya (Solomon, 2009). Untuk dapat membatasi lingkup generasi ini, terdapat pembatasan tahun kelahiran agar tetap mempunyai karakteristik yang serupa yaitu tahun 1977 hingga 1994 (Hawkins dan Mothersbaugh, 2010).

Stefano, dkk (2017) meneliti pengaruh budaya organisasi terhadap deviant behavior di tempat kerja. Tetapi penelitian ini belum mempertimbangkan adanya variabel karakteristik generasi Y sebagai salah satu variabel yang berhubungan dengan deviant behavior. Belum ada penelitian yang mengamati pengaruh karakteristik generasi Y dan budaya organisasi secara bersamaan terhadap deviant workplace behavior. Berdasarkan uraian tersebut, maka perlu dilakukan penelitian untuk mengetahui hubungan kesesuaian antara budaya organisasi dan karakteristik karyawan generasi Y terhadap deviant workplace behavior pada PT. ABC. Untuk mengetahui hubungan ketiga variabel tersebut Penelitian ini menggunakan metode Structural Equation Modeling (SEM). Alasan menggunakan metode SEM adalah: (i) SEM dapat mengetahui hubungan antara beberapa variabel laten sekaligus secara bersamaan; (ii) SEM tidak hanya mengetahui hubungan dengan regresi linier tunggal atau jamak tetapi dengan suatu sistem dari beberapa persamaan regresi (Nachtigall, dkk, 2003). SEM adalah sebuah model statistik yang memberikan perkiraan perhitungan dari kekuatan hubungan hipotesis diantara variabel dalam sebuah model teoritis, baik langsung atau melalui variabel antara (intervening or moderating) (Wijaya, 2001). Berdasarkan tujuan penelitian ini, SEM yang digunakan berbasis covariance atau Covariance Based Structural Equation Modeling (CB-SEM).

Tujuan penelitian adalah untuk mengetahui perilaku umum karyawan generasi Y di PT. ABC; melihat hubungan antara indikator dan variabel laten (budaya organisasi, karakteristik generasi $\mathrm{Y}$ dan deviant workplace behavior); dan melihat hubungan antara budaya organisasi PT. ABC dan perilaku umum generasi Y dengan deviant workplace behavior yang terjadi pada PT. ABC. Penelitian ini diharapkan dapat membantu pihak PT. 
ABC dalam mengatasi masalah deviant workplace behavior yang dilakukan oleh generasi Y. Selain itu, perusahaan dapat menggunakan hasil penelitian ini untuk menyusun strategi pengembangan SDM khususnya generasi Y dengan memaksimalkan karakterisktik potensialnya.

Penelitian mengambil asumsi yaitu: responden diasumsikan memahami setiap pertanyaan yang tertulis pada kuesioner; sampel responden terpilih diasumsikan dapat mewakili populasi karyawan generasi Y; dan tingkat kepercayaan yang digunakan sebesar 95\%. Sedangkan batasan penelitian ini yaitu: responden adalah karyawan yang berumur 24-41 tahun; dan responden merupakan karyawan PT. ABC dengan masa kerja minimal 1 tahun.

\section{Metode Penelitian}

Tahapan penelitian ini dimulai dengan pengumpulan data mengenai budaya organisasi yang diterapkan pada PT. ABC. Tahap ini dilakukan untuk memahami budaya yang diterapkan diperusahaan. Kemudian dilanjutkan dengan menyusun kuesioner untuk mengetahui hubungan antara budaya organisasi dan karakteristik generasi Y terhadap deviant workplace behavior pada PT. ABC. Kuesioner dirancang berdasarkan dimensi dan indikator pada variabel yang sudah ditentukan yaitu variabel karakteristik generasi Y, budaya organisasi PT. $\mathrm{ABC}$, dan deviant workplace behavior. Variabel karakteristik generasi $\mathrm{Y}$ mengacu pada teori Murphy and Davidshofer (2007) yang terdiri dari 7 dimensi yaitu aset, kecenderungan, kriteria atasan, motivasi, pesan yang dapat memotivasi, penghargaan dan metode komunikasi. Variabel budaya organisasi diambil dari budaya organisasi yang sudah ditetapkan pada PT. ABC. Variabel budaya organisasi memiliki 5 dimensi yaitu Concern for People, Integrity, Professional, Teamwork dan Costumer Focused. Variabel deviant workplace behavior mengacu pada teori Speitzer dan Sononhein (2004) dan Robinson dan Benneth (1995). Pada variabel deviant workplace behavior terdapat 8 dimensi yang terdiri Organizational Citizen Behaviors (OCB), Whistle-Blowing, Corporate Social Responsibility (CSR), innovation, penyimpangan produksi, penyimpangan politik, penyimpangan properti dan agresi personal.

Kuesioner yang telah disusun disebar kepada 200 karyawan generasi Y. Setiap responden dimintai pendapatnya dengan memberikan jawaban dari pertanyaan-pertanyaan di dalam kuesioner. Tipe skala yang digunakan dalam penelitian ini adalah skala Likert 1-5. Menurut Prasetyo dan Jannah (2005) skala Likert berisi pernyataan yang sistematis untuk mengasumsikan bahwa masing-masing kategori jawaban ini memiliki intensitas yang sama. Keunggulan indeks ini adalah kategorinya memiliki urutan yang jelas mulai dari "sangat setuju", "setuju", "netral","tidak setuju" dan "sangat tidak setuju". Teknik pemilihan responden menggunakan teknik Accidental Sampling. Accidental Sampling dipilih karena melihat situasi karyawan pada PT. ABC. Jumlah responden dipilih sebanyak 200 orang.

Kuesioner yang telah diisi oleh responden dikumpulkan untuk dilakukan rekapitulasi. Hasil rekapitulasi data tersebut diolah dengan menggunakan metode Structural Equation Modelling (SEM) untuk mengetahui hubungan budaya organisasi PT. ABC dan karakteristik generasi Y terhadap deviant workplace behavior secara bersamaan. Metode SEM dapat digunakan untuk mengetahui hubungan antar variabel laten eksogen terhadap variabel laten endogen dan hubungan antar variabel dan indikatornya. Berikut model SEM untuk diolah dengan program STATA 13 pada Gambar 1.

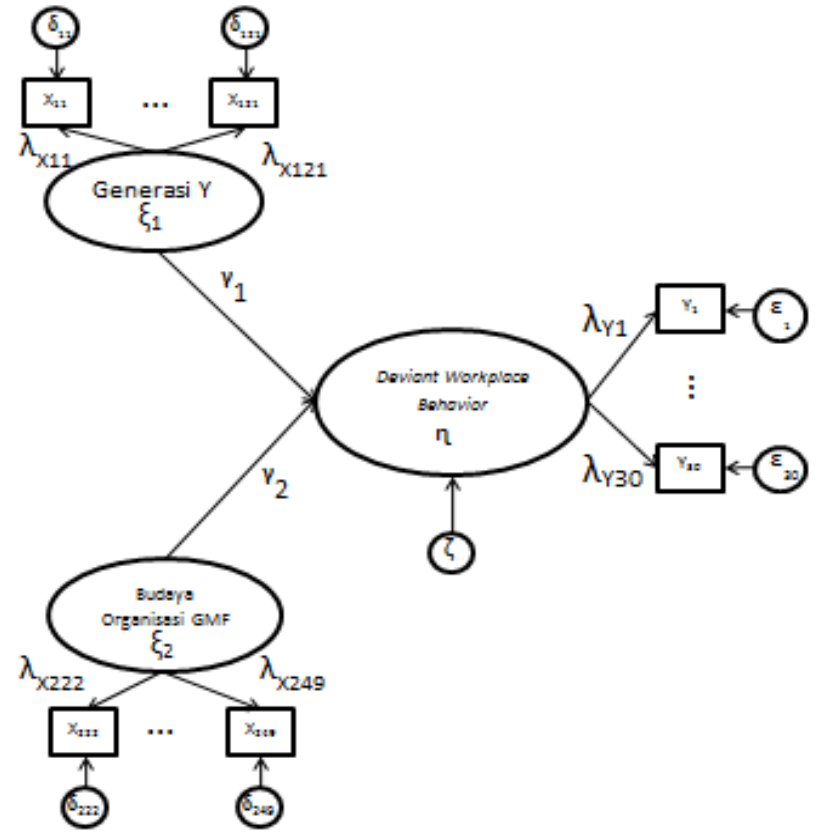

Gambar 1. Model SEM pada STATA 13 
Model pada Gambar 1, terdapat 2 model yaitu model struktural dan model pengukuran. Model struktural menggambarkan hubungan antar variabel laten. Ghozali (2008) menuliskan model persamaan struktural sebagai berikut:

$$
\eta=\beta \eta+\Gamma \xi+\zeta
$$

Keterangan :

$\eta$ : Variabel laten endogen

$\xi$ : Variabel laten eksogen

$\zeta:$ Unexplained variance

Berdasarkan model Ghozali (2008), maka model persamaan struktural yang digunakan adalah sebagai berikut:

$$
\eta=\gamma_{1} \xi_{1}+\gamma_{2} \xi_{2}+\zeta
$$

Model pengukuran menerangkan hubungan antara variabel laten dengan indikatornya. Ghozali (2008) menuliskan persamaan untuk model indikator sebagai berikut:

$$
\begin{aligned}
& \mathrm{X}=\Lambda_{x} \xi+\delta \\
& \mathrm{Y}=\Lambda_{y} \eta+\varepsilon
\end{aligned}
$$

Keterangan :

$\mathrm{X}$ : Indikator variabel laten eksogen

$\mathrm{Y}$ : Indikator variabel laten endogen

$\Lambda_{\mathrm{x}}, \Lambda_{\mathrm{y}}$ : Koefisien regresi sederhana menghubungkan antara variabel laten dan indikatornya

$\delta_{,}{ }_{\varepsilon}:$ Kesalahan pengukuran atau noise

Berdasarkan model Ghozali (2008), maka model persamaan struktural yang digunakan adalah sebagai berikut:

$$
\begin{aligned}
& X_{11}=\Lambda_{x 11} \xi_{1}+\delta_{11} \\
& \quad \cdots \\
& X_{121}=\Lambda_{x 121} \xi_{1}+\delta_{121} \\
& X_{222}=\Lambda_{x 222} \xi_{2}+\delta_{222} \\
& \cdots \\
& X_{249}=\Lambda_{x 249} \xi_{2}+\delta_{249} \\
& Y_{1}=\Lambda_{y 1} \eta+\varepsilon_{1} \\
& \cdots \\
& Y_{30}=\Lambda_{y 30} \eta+\varepsilon_{30}
\end{aligned}
$$

\section{Hasil dan Pembahasan}

Untuk menentukan perilaku umum karyawan generasi Y pada PT. ABC dilakukan pengumpulan data karyawan generasi Y pada PT. ABC. Selanjutnya, pada penelitian ini dilakukan survei menggunakan kuesioner untuk mengetahui perilaku generasi Y pada PT. ABC.

Tabel 1. Jumlah Karyawan Masing-masing Generasi Tahun 2017

\begin{tabular}{|l|r|}
\hline \multicolumn{1}{|c|}{ Generasi } & \multicolumn{1}{c|}{ Total } \\
\hline Baby Boomer & 390 \\
\hline Generasi X & 1.054 \\
\hline Generasi $Y$ & 2.780 \\
\hline Generasi Z & 184 \\
\hline
\end{tabular}

Penyusunan desain kuesioner dilakukan dengan mengolah dimensi dan indikator pada variabel yang sudah ditentukan yaitu variabel budaya organisasi PT. ABC, karakteristik generasi Y dan deviant workplace behavior. Indikator pada setiap dimensi untuk variabel budaya organisasi PT. ABC, karakteristik generasi Y dan deviant workplace behavior dapat dilihat pada tabel 2, tabel 3 dan tabel 4. Dimensi dan indikator dari variabel budaya organisasi dikembangkan berdasarkan budaya organisasi dari PT. ABC. Dimensi dan indikator dari karakteristik generasi Y mengacu pada Murphy and Davidshofer (2007). Sedangkan semua dimensi dan indikator deviant workplace behavior mengacu pada Speitzer dan Sononhein (2004), Near and Miceli (1985), Amabile dkk. 
(1996) serta Robinson dan Benneth (1995) dengan cara menggabungkan dimensi dan indikator dari keempat penelitian tersebut.

Tabel 2. Dimensi dan Indikator Variabel Karakteristik Generasi Y

\begin{tabular}{|c|c|c|}
\hline Dimensi & Indikator & Kode \\
\hline \multirow{4}{*}{ Aset (Modal) } & Aksi kelompok & $\mathrm{X} 1$ \\
\hline & Optimis & $\mathrm{X} 2$ \\
\hline & Multitasking & X3 \\
\hline & Kecerdasan teknologi & $\mathrm{X} 4$ \\
\hline \multirow{2}{*}{ Kecenderungan } & Perlu pengawasan dan struktur & $\mathrm{X} 5$ \\
\hline & Tidak berpengalaman dalam menangani masalah orang lain & $\mathrm{X} 6$ \\
\hline \multirow{3}{*}{ Kriteria Atasan } & Berpengetahuan luas dan mengetahui tujuan pribadi mereka & $\mathrm{X} 7$ \\
\hline & Positif & $\mathrm{X} 8$ \\
\hline & Mendukung dan memberikan pembinaan & $\mathrm{X} 9$ \\
\hline & Kolaboratif & $\mathrm{X} 10$ \\
\hline & Terorganisir dan menciptakan struktur yang wajar & $\mathrm{X} 11$ \\
\hline & Orientasi prestasi & $\mathrm{X} 12$ \\
\hline & Memberikan motivasi & $\mathrm{X} 13$ \\
\hline Motivasi & Atasan yang dapat mengkoneksikan tindakan dengan tujuan pribadi dan karir & $\mathrm{X} 14$ \\
\hline \multirow{3}{*}{$\begin{array}{l}\text { Pesan yang dapat } \\
\text { memotivasi }\end{array}$} & "Anda akan bekerja dengan orang-orang cerdas lainnya, orang kreatif" & $\mathrm{X} 15$ \\
\hline & "Anda dan rekan kerja anda dapat membantu mengubah perusahaan ini" & $\mathrm{X} 16$ \\
\hline & "Anda bisa menjadi pahlawan disini' & $\mathrm{X} 17$ \\
\hline \multirow{3}{*}{ Penghargaan } & Hadiah & $\mathrm{X} 18$ \\
\hline & Sertifikat & $\mathrm{X} 19$ \\
\hline & Penghargaan nyata bukti kredibilitas & $\mathrm{X} 20$ \\
\hline Metode Komunikasi & Kecendrungan berkomunikasi menggunakan pesan singkat, Blog dan E-mail & $\mathrm{X} 21$ \\
\hline
\end{tabular}

Sumber: Murphy and Davidshofer (2007)

Tabel 3. Dimensi dan Indikator Variabel Budaya Organisasi PT. ABC

\begin{tabular}{|c|c|c|}
\hline Dimensi & Indikator & Kode \\
\hline \multirow{6}{*}{ Concern for People } & $\begin{array}{l}\text { Pegawai dapat memberikan pujian dan apresiasi kepada pegawai lain } \\
\text { yang telah bekerja dengan baik. }\end{array}$ & $\mathrm{X} 22$ \\
\hline & $\begin{array}{l}\text { Pegawai dapat menempatkan insan sesuai dengan komposisi dari } \\
\text { kompetensi untuk tercapainya tujuan perusahaan. }\end{array}$ & $\mathrm{X} 23$ \\
\hline & $\begin{array}{l}\text { Pegawai dapat membangun hubungan industrial dan komunikasi yang } \\
\text { baik. }\end{array}$ & $\mathrm{X} 24$ \\
\hline & $\begin{array}{l}\text { Pegawai memiliki komitmen dalam mencapai tujuan individu dan } \\
\text { perusahaan. }\end{array}$ & $\mathrm{X} 25$ \\
\hline & Pegawai mendukung pengembangan kompetensi sesama insan. & $\mathrm{X} 26$ \\
\hline & $\begin{array}{l}\text { Pegawai memberikan rasa aman dan melindungi kepentingan insan } \\
\text { dalam melaksanakan tugas sesuai ketentuan yang berlaku. }\end{array}$ & $\mathrm{X} 27$ \\
\hline \multirow{7}{*}{ Integrity } & Pegawai dapat memegang teguh dan selalu menepati janji. & $\mathrm{X} 28$ \\
\hline & Pegawai dapat tetap bekerja baik dan benar tanpa diawasi. & $\mathrm{X} 29$ \\
\hline & $\begin{array}{l}\text { Pegawai berani menyampaikan kebenaran secara etis didasarkan pada } \\
\text { nilai-nilai perusahaan. }\end{array}$ & $\mathrm{X} 30$ \\
\hline & $\begin{array}{l}\text { Pegawai berani mengakui kekurangan diri dan melakukan upaya } \\
\text { perbaikan nyata. }\end{array}$ & $\mathrm{X} 31$ \\
\hline & $\begin{array}{l}\text { Pegawai mematuhi dan menjalankan etika bisnis dan profesi serta } \\
\text { regulasi dan prosedur. }\end{array}$ & $\mathrm{X} 32$ \\
\hline & $\begin{array}{l}\text { Pegawai dapat menghindari peluang terjadinya benturan kepentingan } \\
\text { antara pribadi dan perusahaan. }\end{array}$ & $\mathrm{X} 33$ \\
\hline & $\begin{array}{l}\text { Pegawai dapat menghadapi tantangan kerja dengan kesungguhan hati dan } \\
\text { ikhlas. }\end{array}$ & X34 \\
\hline \multirow{5}{*}{ Professional } & $\begin{array}{l}\text { Pegawai dapat bekerja sesuai prosedur, peraturan dan spesifikasi yang } \\
\text { berlaku. }\end{array}$ & $\mathrm{X} 35$ \\
\hline & Pegawai disiplin dan sepenuh hati dalam berpikir dan bekerja. & $\mathrm{X} 36$ \\
\hline & $\begin{array}{l}\text { Pegawai dapat meningkatkan pengetahuan dan keterampilan diri sendiri } \\
\text { dan orang lain secara berkelanjutan. }\end{array}$ & $\mathrm{X} 37$ \\
\hline & Pegawai dapat dipercaya, jujur dan loyal terhadap profesi. & $\mathrm{X} 38$ \\
\hline & $\begin{array}{l}\text { Pegawai dapat menfaatkan teknologi informasi dalam bekerja dan } \\
\text { mengikuti perkembangannya. }\end{array}$ & $\mathrm{X} 39$ \\
\hline
\end{tabular}




\begin{tabular}{|c|l|c|}
\multirow{5}{*}{ Teamwork } & Pegawai saling percaya, menghormati dan menghargai. & $\mathrm{X} 40$ \\
\cline { 2 - 3 } & $\begin{array}{l}\text { Pegawai dapat menjadi bagian dari penyelesaian masalah dan fokus dalam } \\
\text { menyelesaikan masalah. }\end{array}$ & $\mathrm{X} 41$ \\
\cline { 2 - 3 } & Pegawai mendukung dan mensukseskan keputusan yang telah diambil. & $\mathrm{X} 42$ \\
\cline { 2 - 3 } Costumer Focused & $\begin{array}{l}\text { Pegawai dapat saling memberikan manfaat. } \\
\text { santun. }\end{array}$ & $\mathrm{X} 43$ \\
\hline \multirow{5}{*}{ Costumer Focused } & $\begin{array}{l}\text { Pegawai dapat memeberikan informasi yang sesuai dan benar kepada } \\
\text { pelanggan. }\end{array}$ & $\mathrm{X} 45$ \\
\cline { 2 - 3 } & $\begin{array}{l}\text { Pegawai mudah dihubungi dan cepat tanggap. } \\
\text { lingkungan perusahaan. }\end{array}$ & $\mathrm{X} 46$ \\
\cline { 2 - 3 } & Pegawai dapat memenuhi komitmen yang telah disepakati. & $\mathrm{X} 47$ \\
\cline { 2 - 3 } & $\begin{array}{l}\text { Pegawai dapat memberikan layanan prima yang disesuaikan dengan } \\
\text { kebutuhan pelanggan. }\end{array}$ & $\mathrm{X} 49$ \\
\hline
\end{tabular}

Sumber: Annual Report PT. ABC

Tabel 4. Dimensi dan Indikator Variabel Deviant Workplace Behavior

\begin{tabular}{|c|c|c|c|}
\hline Dimensi & Indikator & Kode & Sumber \\
\hline $\begin{array}{c}\text { Organizational } \\
\text { Citizen Behaviors }\end{array}$ & Organizational Citizen Behaviors & Y1 & $\begin{array}{c}\text { Speitzer dan } \\
\text { Sonenshein (2004) }\end{array}$ \\
\hline \multirow{3}{*}{ Whistle- Blowing } & Pengungkapan terhadap tindakan ilegal & $\mathrm{Y} 2$ & \multirow{3}{*}{ Near dan Miceli (1985) } \\
\hline & Pengungkapan terhadap tindakan tidak bermoral & Y3 & \\
\hline & Pengungkapan terhadap tindakan tidak sah & Y4 & \\
\hline \multirow{4}{*}{$\begin{array}{l}\text { Corporate Social } \\
\text { Responsibility }\end{array}$} & Program hak asasi manusia & Y5 & \multirow{4}{*}{$\begin{array}{c}\text { Speitzer dan } \\
\text { Sonenshein (2004) }\end{array}$} \\
\hline & Manufaktur ramah lingkungan & Y6 & \\
\hline & Sumbangan amal & Y7 & \\
\hline & Pembangunan ekonomi & Y8 & \\
\hline Innovation & Innovation & Y9 & Amabile dkk. (1996) \\
\hline \multirow{4}{*}{$\begin{array}{l}\text { Penyimpangan } \\
\text { Produksi }\end{array}$} & Pulang kantor lebih cepat & Y10 & \multirow{4}{*}{$\begin{array}{l}\text { Robinson dan Benneth } \\
\text { (1995) }\end{array}$} \\
\hline & Menggunakan jam istirahat berlebihan & Y11 & \\
\hline & sengaja bekerja dengan lambat & Y12 & \\
\hline & Menghabiskan sumber daya & Y13 & \\
\hline \multirow{4}{*}{$\begin{array}{l}\text { Penyimpangan } \\
\text { Politik }\end{array}$} & Menunjukan Favoritsme & Y14 & \multirow{4}{*}{$\begin{array}{l}\text { Robinson dan Benneth } \\
\text { (1995) }\end{array}$} \\
\hline & Menggosip tentang teman kerja & Y15 & \\
\hline & Melimpahkan kesalahan ke teman kerja & Y16 & \\
\hline & Bersaing yang tidak menguntungkan & Y17 & \\
\hline \multirow{4}{*}{$\begin{array}{l}\text { Penyimpangan } \\
\text { Properti }\end{array}$} & Menyabotase peralatan & Y18 & \multirow{4}{*}{$\begin{array}{l}\text { Robinson dan Benneth } \\
\text { (1995) }\end{array}$} \\
\hline & Mencuri dari perusahaan & Y19 & \\
\hline & Menerima suap & $\mathrm{Y} 20$ & \\
\hline & Berbohong tentang jam kerja & Y21 & \\
\hline \multirow{4}{*}{ Pribadi Agresi } & Pelecehan seksual & Y22 & \multirow{4}{*}{$\begin{array}{c}\text { Robinson dan Benneth } \\
\text { (1995) }\end{array}$} \\
\hline & Pelecehan melalui perkataan & $\mathrm{Y} 23, \mathrm{Y} 24, \mathrm{Y} 25$ & \\
\hline & Mencuri dari teman kerja & Y26, Y27 & \\
\hline & Membahayakan teman kerja & Y28,Y29,Y30 & \\
\hline
\end{tabular}

Berdasarkan dimensi dan indikator pada Tabel 2, kemudian dibuat kuesioner yang disebarkan kepada karyawan generasi Y pada PT. ABC. Berikut hasil dari kuesioner dari 200 responden.

Tabel 5. Hasil Kuesioner Untuk Karakteristik Generasi Y pada PT. ABC

\begin{tabular}{|c|c|c|}
\hline No. Penyataan & Mode & Rata-rata \\
\hline X1 & 4 & 4,09 \\
\hline X2 & 4 & 4,325 \\
\hline X3 & 4 & 3,715 \\
\hline X4 & 4 & 3,65 \\
\hline X5 & 4 & 4,23 \\
\hline X6 & 3 & 3,025 \\
\hline X7 & 4 & 3,795 \\
\hline X8 & 4 & 4,1 \\
\hline X10 & 5 & 4,47 \\
\hline X11 & 4 & 4,02 \\
\hline & 4 & 4,135 \\
\hline
\end{tabular}




\begin{tabular}{|c|c|c|}
\hline $\mathrm{X} 12$ & 3 & 3,545 \\
\hline $\mathrm{X} 13$ & 4 & 4,145 \\
\hline $\mathrm{X} 14$ & 4 & 4,03 \\
\hline $\mathrm{X} 15$ & 4 & 3,73 \\
\hline $\mathrm{X} 16$ & 4 & 3,86 \\
\hline $\mathrm{X} 17$ & 3 & 3,34 \\
\hline $\mathrm{X} 18$ & 3 & 3,7 \\
\hline $\mathrm{X} 19$ & 4 & 3,68 \\
\hline $\mathrm{X} 20$ & 3 & 3,615 \\
\hline $\mathrm{X} 21$ & 4 & 3,175 \\
\hline
\end{tabular}

Berdasarkan Tabel 5, responden memilih setuju (4) dan sangat setuju (5) terhadap aksi kelompok, optimis, multitasking, kecerdasan teknologi, perlu pengawasan dan struktur, memilih atasan dengan pengetahuan yang luas, atasan yang positif, atasan yang mendukung dan memberikan pembinaan, atasan yang kolaboratif, atasan yang terorganisir dan menciptakan struktur yang wajar, atasan yang memberikan motivasi, atasan yang dapat mengkoneksikan tindakan dengan tujuan pribadi dan karir, pesan memotivasi seperti "anda akan bekerja dengan orang-orang cerdas dan kreatf", pesan memotivasi seperti “anda dapat mengubah perusahaan ini", penghargaan berupa sertifikat dan kecendrungan berkomunikasi menggunakan pesang singkat, blog dan E-mail menjadi karakteristik karyawan generasi Y pada PT. ABC.

Selanjutnya, untuk mengetahui hubungan antar variabel karakteristik generasi Y dan budaya organisasi terhadap deviant workplace behavior data kuesioner diolah menggunakan STATA 13. Berikut hasil pengolahan data untuk mengetahui hubungan antar variabel generasi Y dan budaya organisasi terhadap varaibel deviant workplace behavior menggunakan STATA 13 pada Tabel 6.

Tabel 6. Hasil Pengolahan Hubungan Antar Variabel dengan STATA 13

\begin{tabular}{|c|rrrrrr|}
\hline & Coef. & $\begin{array}{c}\text { OIM } \\
\text { Std. Err. }\end{array}$ & $\mathbf{z}$ & $\mathrm{p}>|\mathbf{z}|$ & [958 Conf. Interval] \\
\hline $\begin{array}{c}\text { Structural } \\
\text { DWB }<- \\
\text { Generasiy } \\
\text { BudayaGMF }\end{array}$ & 1.48992 & 1.183361 & 1.26 & 0.208 & -.829425 & 3.809265 \\
& .0344081 & .02936 & 1.17 & 0.241 & -.0231365 & .0919527 \\
\hline
\end{tabular}

Pada Tabel 6, nilai -p pada variabel generasi $\mathrm{Y}$ adalah 0,208 yang lebih besar dari taraf signifikan 0,05 sehingga dapat dikatakan bahwa pengaruh generasi Y pada variabel deviant workplace behavior tidak signifikan. Nilai - p pada variabel budaya organisasi adalah 0,241 yang lebih besar dari taraf signifikan 0,05 yang berarti pengaruh budaya organisasi tidak signifikan.

Tabel 7. Hasil Pengolahan Hubungan Variabel dengan Indikatornya Menggunakan STATA 13

\begin{tabular}{|c|c|c|c|c|c|c|c|c|c|c|c|}
\hline Kode & Nilai-p & Kode & Nilai-p & Kode & Nilai-p & Kode & Nilai-p & Kode & Nilai-p & Kode & Nilai-p \\
\hline X1 & 0,000 & X16 & 0,156 & X31 & 0,000 & X46 & 0,000 & Y12 & 0,005 & Y27 & 0,003 \\
\hline X2 & 0,216 & X17 & 0,162 & X32 & 0,000 & X47 & 0,000 & Y13 & 0,004 & Y28 & 0,003 \\
\hline X3 & 0,607 & X18 & 0,174 & X33 & 0,000 & X48 & 0,000 & Y14 & 0,004 & Y29 & 0,003 \\
\hline X4 & 0,171 & X19 & 0,174 & X34 & 0,000 & X49 & 0,000 & Y15 & 0,003 & Y30 & 0,003 \\
\hline X5 & 0,159 & X20 & 0,167 & X35 & 0,000 & Y1 & 0,000 & Y16 & 0,003 & & \\
\hline X6 & 0,453 & X21 & 0,481 & X36 & 0,000 & Y2 & 0,149 & Y17 & 0,003 & & \\
\hline X7 & 0,153 & X22 & 0,000 & X37 & 0,000 & Y3 & 0,712 & Y18 & 0,003 & & \\
\hline X8 & 0,154 & X23 & 0,000 & X38 & 0,000 & Y4 & 0,062 & Y19 & 0,003 & & \\
\hline X9 & 0,151 & X24 & 0,000 & X39 & 0,000 & Y5 & 0,204 & Y20 & 0,003 & & \\
\hline X10 & 0,152 & X25 & 0,000 & X40 & 0,000 & Y6 & 0,081 & Y21 & 0,003 & & \\
\hline X11 & 0,154 & X26 & 0,000 & X41 & 0,000 & Y7 & 0,492 & Y22 & 0,003 & & \\
\hline X12 & 0,155 & X27 & 0,000 & X42 & 0,000 & Y8 & 0,872 & Y23 & 0,003 & & \\
\hline X13 & 0,152 & X28 & 0,000 & X43 & 0,000 & Y9 & 0,106 & Y24 & 0,003 & & \\
\hline X14 & 0,160 & X29 & 0,000 & X44 & 0,000 & Y10 & 0,004 & Y25 & 0,003 & & \\
\hline X15 & 0,160 & X30 & 0,000 & X45 & 0,000 & Y11 & 0,004 & Y26 & 0,003 & & \\
\hline
\end{tabular}

Pada Tabel 7, terdapat hasil pengolahan menggunakan STATA 13 untuk mengetahui hubungan antara variabel dengan indikator-indikatornya. Pada STATA 13, dapat dilihat bahwa indikator yang berperngaruh 
signifikan pada variabel karakteristik generasi Y adalah indikator pernyataan yang memiliki nilai-p lebih kecil dari taraf signifikansi yaitu 0,05 .

Hasil pengolahan variabel karakteristik generasi Y pada Tabel 7 menunjukan bahwa pernyataan X2, X3, X4, X5, X6, X7, X8, X9, X10, X11, X12, X13, X14, X15, X16, X17, X18, X19, X20 dan X21 memiliki nilaip yang lebih besar dari taraf signifikansi. Sedangkan X1 memiliki nilai-p lebih kecil dari taraf signifikansi. Sehingga pernyataan X1 atau aksi kelompok memiliki pengaruh yang signifikan terhadap karakteristik karyawan generasi Y pada PT. ABC. Sedangkan pernyataan X2 sampai X21 tidak memiliki pengaruh yang signifikan terhadap karakteristik karyawan generasi Y pada PT. ABC.

Hasil pengolahan variabel budaya organisasi PT. ABC pada Tabel 7 menunjukan bahwa pernyataan X22, X23, X24, X25, X26, X27, X28, X29, X30, X31, X32, X33, X34, X35, X36, X37, X38, X39, X40, X41, X42, X43, X44, X45, X46, X47, X48 dan X49 memiliki nilai-p lebih kecil dari taraf signifikan.

Hasil pengolahan variabel karakteristik generasi Y pada Tabel 7 menunjukan bahwa pernyataan Y2, Y3, Y4, Y5, Y6, Y7, Y8 dan Y9 memiliki nilai-p yang lebih besar dari taraf signifikansi. Sedangkan Y1, Y10, Y11, Y12, Y13, Y14, Y15, Y16, Y17, Y18, Y19, Y20, Y21, Y22, Y23, Y24, Y25, Y26, Y27, Y28, Y29 dan Y30 memiliki nilai-p lebih kecil dari taraf signifikan.

Pada hasil STATA tersebut beberapa pernyataan memiliki nilai - p yang lebih besar dari taraf signifikan. Hal ini disebabkan karena respon dari responden yang beragam. Contohnya pada permyataan X21 yang memiliki nilai-p yang lebih besar dari taraf signifikan, hal ini disebabkan responden yang memilih sangat tidak setuju sebesar 5,5\%, tidak setuju sebesar $21,5 \%$, netral sebesar $28 \%$, setuju sebesar $40 \%$ dan sangat setuju sebesar $5 \%$ terhadap pernyataan untuk indikator metode komunikasi.

\section{Kesimpulan}

Variabel karakteristik generasi Y dan budaya organisasi PT. ABC tidak memiliki pengaruh yang signifikan terhadap masalah deviant workplace behavior. Indikator karakteristik aksi kelompok memiliki pengaruh yang signifikan terhadap variabel karakteristik karyawan generasi Y di PT. ABC. Semua indikator pada variabel budaya organisasi memiliki pengaruh yang signifikan terhadap variabel budaya organisasi pada PT. ABC. Indikator organizational citizen behaviors, pulang kantor lebih cepat, menggunakan jam istirahat berlebihan, sengaja bekerja dengan lambat, menghabiskan sumber daya, menunjukan favoritsme, menggosip tentang teman kerja, melimpahkan kesalahan ke teman kerja, bersaing yang tidak menguntungkan, menyabotase peralatan, mencuri dari perusahaan, menerima suap, berbohong tentang jam kerja, pelecehan seksual, pelecehan melalui perkataan, mencuri dari teman kerja dan membahayakan teman kerja memiliki pengaruh yang signifikan terhadap variabel deviant workplace behavior.

Karyawan generasi Y pada PT. ABC belum sepenuhnya memiliki karakteristik generasi Y yang berpengaruh seperti pendapat Murphy and Davidshofer (2007). Hal ini menunjukkan bahwa karyawan generasi Y pada PT. ABC belum mengembangkan potensi yang seharusnya dimiliki oleh generasi Y, seperti: potensi optimis dan multitasking. Namun karyawan generasi Y pada PT. ABC memiliki pengaruh yang kuat pada bidang aksi kelompok yang juga merupakan salah satu nilai budaya organisasi yang diterapkan oleh PT. ABC. Sehingga dalam meningkatkan budaya organisasi karyawan generasi Y, PT. ABC dapat memanfaatkan nilai teamwork yang dimiliki oleh karyawan generasi $\mathrm{Y}$.

Pihak PT. ABC dapat meningkatkan potensi dari karyawan generasi Y dengan menciptakan lingkungan yang merangsang berkembangnya potensi tersebut. Perlu dilakukan riset lebih lanjut untuk mengetahui aspekaspek lain yang mempengaruhi terjadinya deviant workplace behavior. Selain itu perlu dilakukan riset pengembangan model untuk menyelesaikan masalah deviant workplace behavior yang dilakukan oleh karyawan generasi Y pada PT. ABC.

\section{Daftar Pustaka}

Annual Report PT. ABC (2015). diunduh pada 23 Maret 2017.

Amabile, T.M., Conti, R., Coon, H., Lazenby, J. \& Herron, M. (1996), Assessing the work environment for creativity, Academy of Management Journal, Vol. 39 No. 5, pp. 1154-84.

Appelbaum, S. H., Nadeau, D., \& Cyr, M. (2008). Performance evaluation in a matrix organization : a case study (Part Two). Industrial and Commercial Training, Vol.40, No.6, pp:295-299

Appelbaum, S. H. (2007). Positive and Negative Deviant Workplace Behavior: Causes, Impact, and Solutions. Corporate Governance International Journal of Business in Society, Vol.7 No.5, pp.586-598

Bappenas (2015). Statistik Pemuda Indonesia, diunduh pada 11 April 2017.

Budiman. (2008). Company Profile. Jakarta: Universitas Gunadarma. 
De Meuse, K. (2009). A Scholarly Investigation of Generational Workforce Differences: Debunking the Myths. Korn/Ferry International. Los Angeles: CA.

Di Stefano, G., Scrima, F., \& Parry, E. (2017). The effect of organizational culture on deviant behaviors in the workplace, International Journal of Human Resource Management. pp. 1-22

Ghozali, I. (2008), Model Persamaan Struktural Konsep dan Aplikasi dengan Program Amos 16.0, Semarang: Badan Penerbit UNDIP.

Hawkins, D.I. \& Mothersbaugh, D.L. (2010). Consumer Behavior: Building Marketing Strategy.11th edition. New York: Mc GrawHill.

Mannheim, K. (1923). The problem of Generation, London: Routledge \& Kegan Paul.

Nachtigall, C., Kroehne, U., Funke, F., \& Steyer, R. (2003). (Why) Should We Use SEM? Pros and Cons of Structural Equation Modeling, Methods of Psychological Research Online, Vol.8, No.2, pp. 1-22

Near, J. P., \& Miceli, M. P. (1985). Organizational dissidence. The case of whistle-blowing, Journal of Business Ethics, 4: 1-16.

Nurcahyo, R.J. (2015). Keterkaitan Visi, Misi dan Values Kinerja Karyawan Perusahaan Kulit "Dwi Jaya". Jurnal Khasanah Ilmu, Vol. 6 No. 2

Murphy, K. R. \& Davidshofer, C.O. (2007). Psychological testing: Principles and application. New Jersey: Prentice-Hall Inc

Nawawi, H. (2005). Manajemen Sumber Daya Manusia Untuk Bisnis yang Kompetitif .Cetakan Keempat, Yogyakarta : Penerbit Gajah Mada University Press

Prasetyo, B. \& Jannah, L.M. (2005). Metode Penelitian Kuantitatif: Teori dan Aplikasi, Jakarta: Raja Grafindo Persada.

Robbins, S. (2008). Organizational Behavoir (Perilaku Organisasi). Jakarta: PT. Macanan Jaya

Robinson, S.L. \& Bennett, R.J. (1995), A typology of Deviant Workplace Behavior: A Multidimensional Scaling Study. Academy of Management Journal, Vol. 38 No. 2, pp. 555-572.

Solomon, M.R. \& Rabolt, N. (2009). Consumer Behavior in Fashion, 2nd Edition. USA: Prentice Hall

Wijaya (2001). Statistika Non Parametrik (Aplikasi Program SPSS), Bandung: ALFABETA.CV 